\title{
An Revised Factors Model for Estimation and Prediction of Greenhous Gas Emission in Wastewater Treatment Plant
}

\author{
Zhang Qianyun ${ }^{1, a}$, Xu Ling ${ }^{2, b}$ and Li Jiannan ${ }^{3, c}$ \\ ${ }^{1}$ Environmental Building 304, Ganjingzi District, Dalian City, Liaoning Province, China \\ ${ }^{2}$ Environmental Building 304, Ganjingzi District, Dalian City, Liaoning Province, China \\ ${ }^{3}$ Environmental Building 304, Ganjingzi District, Dalian City, Liaoning Province, China \\ a'savannahzhang1990@hotmai.com, b55967585@qq.com, c lijiannan2008@mail.dlut.edu.cn
}

Keywords: Greenhouse gas; Wastewater treatment; Expert scoring method; Hybrid process.

Abstract. A comprehensive mathematical model has been revised to estimate greenhouse gas (GHG) emissions by urban wastewater treatment plants (WWTP) resulting from on-site activities. The contribution of individual processes and well-management levels of WWTPs to the production of GHGs in hybrid treatment system has been determined. Using the revised mathematical model, we estimate the total $\mathrm{CO}_{2}$ equivalent mass and per unit COD removal mass of emission in Dalian City from year 2004 to 2013. According to the results, our prediction is that the overall $\mathrm{CO}_{2}$ equivalent mass of emission will continue to increase, but improvement of wastewater treatment technology and automatic detection can efficiently reduce the growth. The revised emission factor of GHG emissions from nutrient removal in the overall GHG emissions of WWTPs increased the accuracy and completeness of this estimation, lending support to the novelty of the present study.

\section{Introduction}

The IPCC's fourth assessment report pointed out that the rising concentrations of greenhouse gases (GHGs) in the atmosphere is one of the main factors of global warming ${ }^{[1]}$. The reduction of GHG emissions in this system has great potential ${ }^{[2]}$, but the relevant domestic research is presently inadequate. In the real situation the recommended default value can't exactly reflect the real characteristics of emissions of GHGs in urban WWTPs, which often changes by the characteristics. So using the default value will reduce the accuracy of the estimation greatly ${ }^{[3]}$. Considering this situation, the study suggested a more accurate estimation which requires adjusting the default values on the basis of good practice recommended.

\section{Methodology}

For data limited state, using the GHG emission factors and the activity data to estimating is a good practice[4]. In this paper, we have done some adjustment to the existing methods and ideas by using expert scoring method. And we investigated and survived all the WWTPs in Dalian City from 2004 to 2013, the contents are the key impacting factors, which are sewage treatment processes, sewage load, management operations.

\section{Determination of emission factors}

(1) Determine the evaluation factors

According to field investigation results, the main evaluation standard of wastewater treatment process is: anaerobic tank, anaerobic reactions in aerobic process. The key evaluation standards of management levels are: anaerobic reactions in plants, which mainly operated by aerobic process, caused by equipment management.

(2) Evaluation standards of expert scoring method

According to the survey results, we grade all the treatment processes between $0-1$, which were used in Dalian City from 2004 to 2013 in this paper (table 1). According to 
Table 1

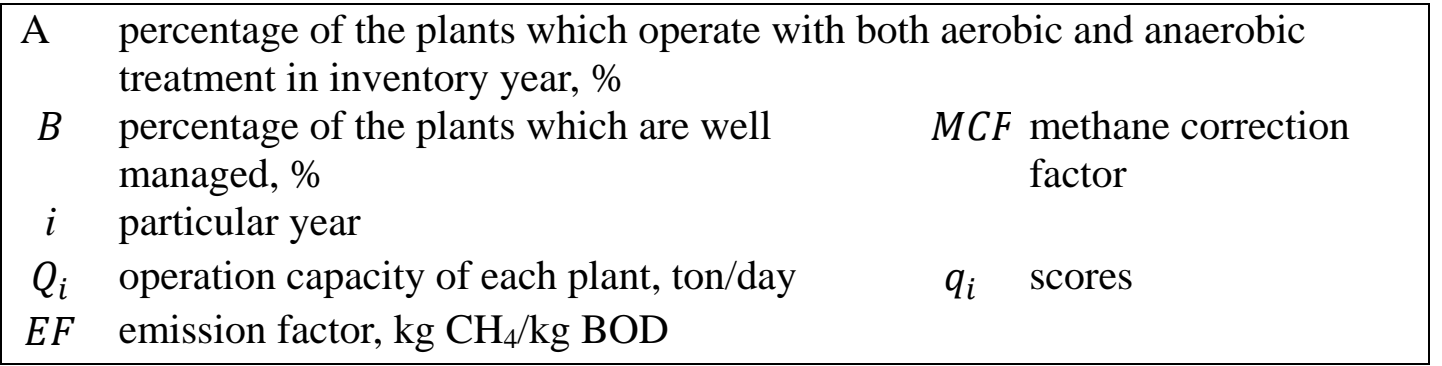

different anaerobic degree, we average the results using expert scoring method. Then we can use the following formula to get the evaluation factor of every year:

$$
\mathrm{A}=\frac{\sum_{i=1}^{n} Q_{i} \times q_{i}}{\sum_{i=1}^{n} Q_{i}} \times 100
$$

Table 2 Evaluation standards of wastewater treatment processes

\begin{tabular}{|c|c|c|c|c|c|c|}
\hline Evaluation Factor (treatment process) & AS & BAF & CAST & SBR & $\mathrm{A}_{2} / \mathrm{O}$ & $\mathrm{A} / \mathrm{O}$ \\
\hline Score $\left(q_{j}\right)$ & 0.1 & 0.3 & 0.7 & 0.9 & 1 & 1 \\
\hline
\end{tabular}

We grade the management level from 1 to 0 for all the urban wastewater plants in Dalian City, using the survey results (table 3). By using the following formula, we can get the final evaluation result.

$B=\frac{\sum_{i=1}^{n} Q_{i} q_{i}}{\sum_{i=1}^{n} Q_{i}} \times 100$

(3) Choice methane emission factors

According to the experts' opinions, we believe that for wastewater plants that run by both aerobic and anaerobic treatments, 25\% pollutants are removed in anaerobic

Table 3 Evaluation standards of well-management level

\begin{tabular}{|c|c|c|c|}
\hline Evaluation Factor & Production and Operation & Equipment & Laboratory \\
\hline Score $\left(q_{j}\right)$ & 0.4 & 0.4 & 0.2 \\
\hline
\end{tabular}

phase, and 75\% removed in aerobic phase. The annual MCF value calculation process and results of sewage treatment plant in table 4.

Table 4 Calculation method of $M C F_{i}$ of WWTP

\begin{tabular}{ccc}
\hline Treatment Process & $W S_{i}$ & $M C F_{i}$ \\
Anaerobic Treatment & $\mathrm{A} \% \times 25 \%$ & 0.8 \\
Aerobic Treatment but not well managed & $(1-\mathrm{A} \% \times 25 \%) \times(1-\mathrm{B} \%)$ & 0.3 \\
Aerobic Treatment and well managed & $(1-\mathrm{A} \% \times 25 \%) \times \mathrm{B} \%$ & 0 \\
\hline \multicolumn{2}{c}{$M C F=A \% \times 25 \% \times 0.8+(1-A \% \times 25 \%) \times(1-B \%) \times 0.3$} \\
\hline
\end{tabular}

\section{Results}

Emission of $\mathrm{CH}_{\mathbf{4}}$ from wastewater treatment.According to the estimation mode recommended by GPG2000, the revised emission factors and the data from Chinese statistical yearbook [5], the MCF is calculated in table 5 . The methane emission mass is increased year by year, with the annual average increasing rate of $7.48 \%$. The main reason is the substantia increase of processing capacity, rising from 5 plants, capacity of 372000 tons of sewage in 2004 to 25 plants, capacity of 1.317 million tons of sewage in 2013.

But the revised emission factors can have small range of fluctuation on methane emission mass. According to the result, we can predict that the $\mathrm{CH} 4$ emission mass will continue to increase. But 
the $\mathrm{CH} 4$ emission mass can be reduced in a relatively small range with the technological innovation and management upgrading of wastewater processing.

Table 5. MCF from WWTPs of Dalian City in year 2004-2013

\begin{tabular}{ccccccccccc}
\hline Year & 2004 & 2005 & 2006 & 2007 & 2008 & 2009 & 2010 & 2011 & 2012 & 2013 \\
\hline MCF & 0.189 & 0.171 & 0.161 & 0.159 & 0.145 & 0.138 & 0.129 & 0.134 & 0.136 & 0.132 \\
\hline
\end{tabular}

Emission of $\mathrm{CO}_{2}$ equivalent from wastewater treatment.In order to ensure continuity and comparability of the international GHG emissions data, we followed the requirements by the UN framework convention on climate change (UNFCCC) to converted $\mathrm{CH} 4$ and $\mathrm{N} 2 \mathrm{O}$ into $\mathrm{CO} 2$ equivalent and added them. And this paper calculates the per capita of total GHG CO2 equivalent emissions
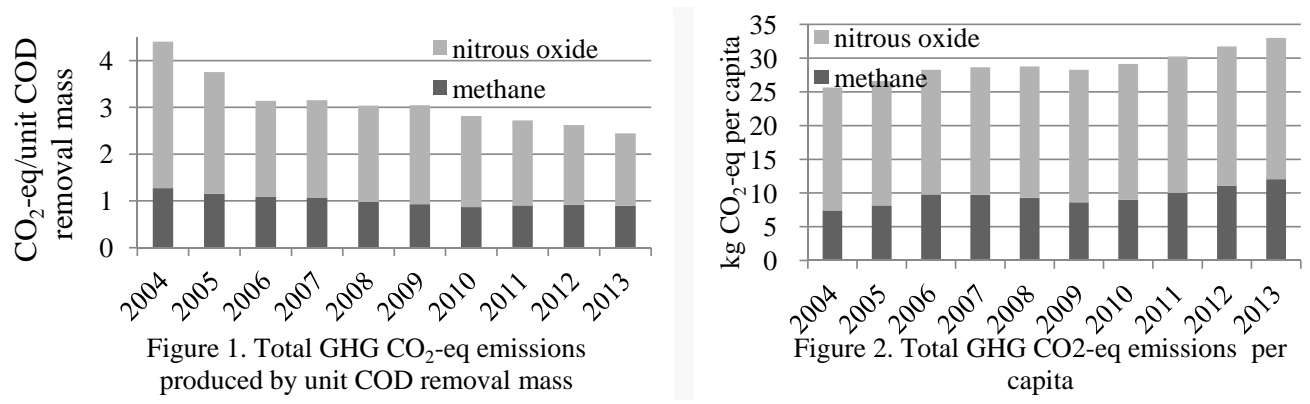

produced by per COD removal mass unit. Figure 1 shows the total emissions produced by unit COD removal mass, the annual average decreasing rate of 6.05\%. Figure 2 shows the per capita of total GHG emissions, the growth number is from $25.6 \mathrm{~kg}$ CO2-eq/year in 2004 to $33.06 \mathrm{~kg}$ CO2-eq/year in 2013.

After presenting all the data from 2004 to 2013, we hold the opinion that the amount of CH4 and N2O produced by WWTPs increased year by year. And the trend that emissions produced by unit COD removal mass gradually reduced shows the new wastewater treatment technology has positive influence on GHG emission control.

\section{Summary}

(1) During 2004-2013, CH4 and N2O emissions of municipal WWTPs in Dalian City are keep increasing year by year. Per capita $\mathrm{CO} 2$ equivalent emissions increases with population growth, but the total emissions per unit COD removal mass decreased with time. It shows that the addition of population is key factor to addition of COD removal mass.

(2) WWTPs should focus on decreasing anaerobic treatment processing, improving automatic detection, using upgradation technology and recycling methane gas.

\section{Acknowledgements}

This work was financially supported by the Shanghai Natural Science Foundation (0666666), Innovation Program of Shanghai Municipal Education Commission (060000) and Shanghai Leading Academic Discipline Project of Shanghai Municipal Education Commission (0555555).

\section{References}

[1] 秦大河, 陈振林, 等. 气候变化科学的最新认知[J]. 气候变化研究进展, 2007, 02:63-73.

[2] EPA. Global Mitigation of Non-CO ${ }_{2}$ Greenhouse Gases: 2010-2030[R]. 2013

[3] Coalition Global Water Research. $\mathrm{N}_{2} \mathrm{O}$ and $\mathrm{CH}_{4}$ Emission from Wastewater Collection and Treatment Systems Technical Report[R].2011 
[4] IPCC. 2006 IPCC guidelines for national greenhouse gas inventories [M]. Kanagawa: Institute for Global Environmental Strategies, 2006

[5] 中华人民共和国环保部. 中国环境统计年报（2004-2013）[M]. 北京：中国环境出版社， 2004-2013. 